06.5

\title{
Морфология и структурное состояние частиц нанопорошков, полученных измельчением природного алмаза и методом детонационного синтеза
}

\author{
(С) П.П. Шарин ${ }^{1}$, А.В. Сивцева ${ }^{1}$, В.И. Попов ${ }^{2}$ \\ ${ }^{1}$ Институт фризико-технических проблем Севера им. В.П. Ларионова при ФИЦ „Якутский научный центр СО РАН“, \\ Якутск, Россия \\ ${ }^{2}$ Северо-Восточный фредеральный университет им. М.К. Аммосова, Якутск, Россия \\ E-mail: psharin1960@mail.ru
}

Поступило в Редакцию 20 сентября 2019 г.

В окончательной редакции 31 октября 2019 г.

Принято к публикации 7 ноября 2019 г.

С помощью комплекса высокоразрешающих методов показано, что в отличие от нанопорошка детонационного синтеза, состоящего в основном из близких по размеру и изометрических частиц, частицы нанопорошка, полученные измельчением природного алмаза, имеют более широкий разброс по размерам и преимущественно пластинчатую форму. Первичные частицы нанопорошка, полученного измельчением, так же как и наноалмазы детонационного синтеза, состоят из алмазных ядер, имеющих кубические кристаллические решетки, окруженные оболочками со сложными структурами, образованными из атомов углерода в $s p^{2}$-состоянии и примесей. Установлено заметное увеличение межатомных расстояний в нанодисперсных кристаллах алмаза по сравнению с таковыми для крупных кристаллов алмаза.

Ключевые слова: измельчение, наноалмазы, структура нанокристалла, оболочка, межатомное расстояние.

DOI: 10.21883/PJTF.2020.03.48993.18045

Изучение структуры первичных частиц нанодисперсных алмазных порошков, сочетающих уникальные механические, оптические и электронные свойства с биосовместимостью и необычными физико-химическими свойствами их поверхности, привлекает интерес с точки зрения как фундаментальной, так и прикладной науки [1]. Из двух альтернативных подходов получения наноструктурных материалов на данный момент наиболее используемым при синтезе наночастиц алмаза является так называемый подход „снизу вверх“, основанный на процессе соединения атомов углерода в нанокристаллы алмаза при детонации углеродсодержащих взрывчатых веществ в замкнутом объеме с отрицательным кислородным балансом [1-3]. Однако метод детонационного синтеза имеет ряд недостатков, связанных с применением дорогостоящих взрывных камер и не менее затратными и сложными технологическими процессами извлечения и очистки наночастиц алмаза из сопутствующих продуктов синтеза. Альтернативный подход „сверху вниз“, основанный на измельчении крупных алмазов природного происхождения или статического синтеза, в сочетании с методами центрифугирования является сравнительно простым и управляемым способом производства нанокластеров алмаза и может обеспечить получение наночастиц алмаза с контролируемыми и воспроизводимыми характеристиками $[1,4]$. При измельчении в качестве исходного материала предпочтительно использование природных алмазов, поскольку по сравнению с синтетическими алмазами они содержат малое количество металлических или иных примесей и дефектов.
Цель настоящей работы - изучение и сравнительный анализ морфологии и структурных характеристик первичных частиц нанопорошков, полученных двумя способами: механическим измельчением природного алмаза и методом детонационного синтеза.

Нанопорошок из природного алмаза (ПНА) получен измельчением при помощи вибрационной мельницы (в режиме мокрого помола), в которой мелющими элементами служили стальные шарики диаметром 6-11 mm [5]. В качестве исходного сырья использовалась фракция $(-40 \mu \mathrm{m})$ микропорошка природного алмаза. Химическая очистка нанопорошка от примесей, образующихся в процессе измельчения, проводилась путем их последовательной обработки в кипящих смесях кислот $\mathrm{HNO}_{3}$ и $\mathrm{H}_{2} \mathrm{SO}_{4}, \mathrm{HNO}_{3}$ и $\mathrm{HCl}$, а затем раствором $\mathrm{NaOH}$ с последующей многократной промывкой дистиллированной водой. Для снижения потерь нанодисперсных частиц алмаза при смене реактивов и промывке их водой использовались лабораторная центрифуга марки Jouan C3i и ультразвуковой диспергатор марки Fritsch Laborette 17. Выход наночастиц алмазного порошка в сухом виде после измельчения, химочистки и сушки составил 78-85\% от веса исходного природного алмазного сырья. Полученный сухой нанопорошок ПНА имеет светло-серый цвет, тогда как нанопорошок детонационного синтеза (ДНА) марки УДА-С-ГО производства ФНПЦ „Алтай“, использованный в качестве образца при проведении сравнительных исследований, окрашен в коричневый цвет. 

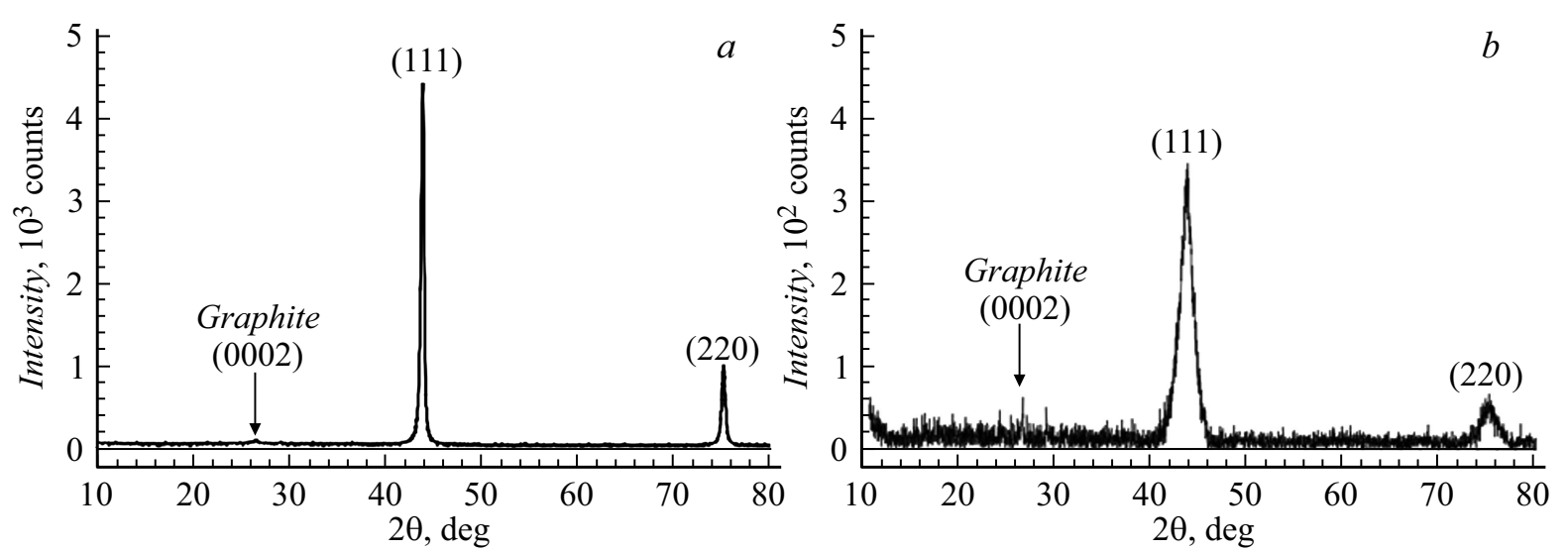

Рис. 1. Дифракционные спектры образцов нанопорошков ПНА $(a)$ и ДНА $(b)$.

Плотности нанопорошков ПНА и ДНА, измеренные методом жидкостной пикнометрии, составили соответственно $\sim 3.05$ и $\sim 2.95 \mathrm{~g} / \mathrm{cm}^{3}$, что значительно ниже теоретической плотности алмаза $\left(3.5154 \mathrm{~g} / \mathrm{cm}^{3}\right)$ и плотности крупных природных кристаллов алмаза, которая в зависимости от содержания в них примесей колеблется в пределах $3.30-3.60 \mathrm{~g} / \mathrm{cm}^{3}$ [1,3]. Значения удельной поверхности нанопорошков ПНА и ДНА, определенные методом Брунауэра-Эммета-Теллера (BET) по данным измерений низкотемпературной адсорбции молекул азота $(77 \mathrm{~K})$, составили соответственно $\sim 33.4$ и $\sim 338.6 \mathrm{~m}^{2} / \mathrm{g}$. Размеры первичных частиц нанопорошков, измеренные методами рентгеноструктурного фазового анализа (РФА) и малоуглового рентгеновского рассеяния (МРP), были равны соответственно для частиц ПНА $\sim 25.9$ и $\sim 24.0 \mathrm{~nm}$, для частиц ДНА $\sim 5.0$ и $\sim 5.6 \mathrm{~nm}$. В зависимости от метода определения средний размер первичных частиц ПНА в $~ 4.29$ раза (МРР) или $\sim 5.18$ раза (РФА) превышает размеры частиц ДНА, тогда как значения их удельной поверхности различаются более чем в 10 раз, что указывает на существенное различие формы их первичных частиц. Аналитическая обработка полученных с помощью высокоразрешающих просвечивающего (ПЭМ) (Titan 80-300 FEI, США) и растрового (PЭМ) (JSM-6480LV, JEOL, Япония) электронных микроскопов прямых ПЭМ- и РЭМ-изображений образцов нанопорошков позволила установить, что в отличие от нанопорошка ДНА, состоящего из близких по размеру частиц в основном ( $~ 84 \%$ от всего количества подвергнутых обработке) изометрических форм (сфера или куб), нанопорошок ПНА содержит частицы, имеющие не только более широкий разброс по размерам, чем частицы ДНА, но и преимущественно пластинчатую форму ( $74 \%$ от всех частиц подвергнутых обработке). Оценка по эвристической формуле

$$
D=k /\left(\rho S_{\mathrm{BET}}\right),
$$

связывающей размер частиц $D$, удельную поверхность $S_{\mathrm{BET}}$, плотность $\rho$ при коэффициенте $k$, равном 2 (для частиц, имеющих пластинчатую форму) или 6 (для частиц, имеющих сферическую форму), дает для $D$ результаты, удовлетворительно совпадающие со средними размерами частиц ПНА и ДНА, определенными методами РФА и МРР.

На рис. 1 приведены дифракционные спектры, полученные с помощью дифрактометра ARL X'Tra фирмы Thermo Fisher Scientific (Швейцария) с использованием $\mathrm{Cu} K_{\alpha}$-излучения $(\lambda=1.541 \AA)$. Наблюдаемые четкие пики в спектре нанопорошка ПНА при углах $2 \theta \sim 43.89$ и $\sim 75.25^{\circ}$ и в спектре нанопорошка ДНА при углах $2 \theta \sim 43.62$ и $\sim 75.21^{\circ}$ соответствуют дифракции рентгеновского излучения на атомных плоскостях (111) и (220) кристаллической решетки алмаза. Едва заметные линии в спектрах ПНА и ДНА при углах $2 \theta$, равных $\sim 26.44$ и $\sim 26.56^{\circ}$, соответствуют дифракции рентгеновского излучения на плоскости (0002) решетки графита [6]. В табл. 1 представлены параметры структуры первичных частиц нанопорошков ПНА и ДНА, полученные в результате аналитической обработки их дифракционных спектров. Межплоскостные расстояния решеток $d_{h k l}$ нанокристаллов рассчитывались по формуле Вульфа-Брэгга

$$
2 d_{h k l} \sin \theta_{h k l}=n \lambda
$$

Для сравнения в табл. 1 также приведены структурные параметры массивного кристалла алмаза из базы данных [7].

На рис. 2 показаны изображения нанокристаллов ПНА $(a)$ и ДНА $(b)$, полученные в режиме светлого поля с помощью высокоразрешающего ПЭМ. На средней вставке на рис. 2, а приведены РЭМ-изображения частиц ПНА, имеющих преимущественно пластинчатую форму. На ПЭМ-изображениях четко видны и разрешены ряды атомных плоскостей (111) и (220) нанокристаллов ПНА и ДНА, являющихся составными элементами системы плоскостей, формирующих кубическую кристаллическую решетку алмаза. Получение качественных ПЭМизображений позволяет определить по ним структурные 
Таблица 1. Значения углов сканирования $(2 \theta)$, межплоскостных расстояний $\left(d_{h k l}\right)$, физического уширения $(\beta)$, параметров решетки $(a)$ для крупного кристалла алмаза, нанокристаллов ПНА и ДНА

\begin{tabular}{c|c|c|c|c|c|c|c|c|c|c|c}
\hline \multirow{2}{*}{$\begin{array}{c}\text { Индексы } \\
\text { Миллера }\end{array}$} & \multicolumn{2}{|c|}{ Массивный кристалл алмаза } & \multicolumn{4}{c|}{ ПНА } & \multicolumn{4}{c}{ ДНА } \\
\cline { 2 - 13 } & $2 \theta, \mathrm{deg}$ & $d_{h k l}, \AA$ & $a, \AA$ & $2 \theta, \mathrm{deg}$ & $d_{h k l}, \AA$ & $\beta, \mathrm{deg}$ & $a, \AA$ & $2 \theta, \operatorname{deg}$ & $d_{h k l}, \AA$ & $\beta, \mathrm{deg}$ & $a, \AA$ \\
\hline 111 & 43.93 & 2.059 & \multirow{2}{*}{3.567} & 43.89 & 2.061 & 0.37 & \multirow{2}{*}{3.569} & 43.62 & 2.073 & 1.84 & 3.581 \\
220 & 75.29 & 1.261 & & 75.25 & 1.262 & 0.38 & & 75.21 & 1.262 & 2.05 &
\end{tabular}
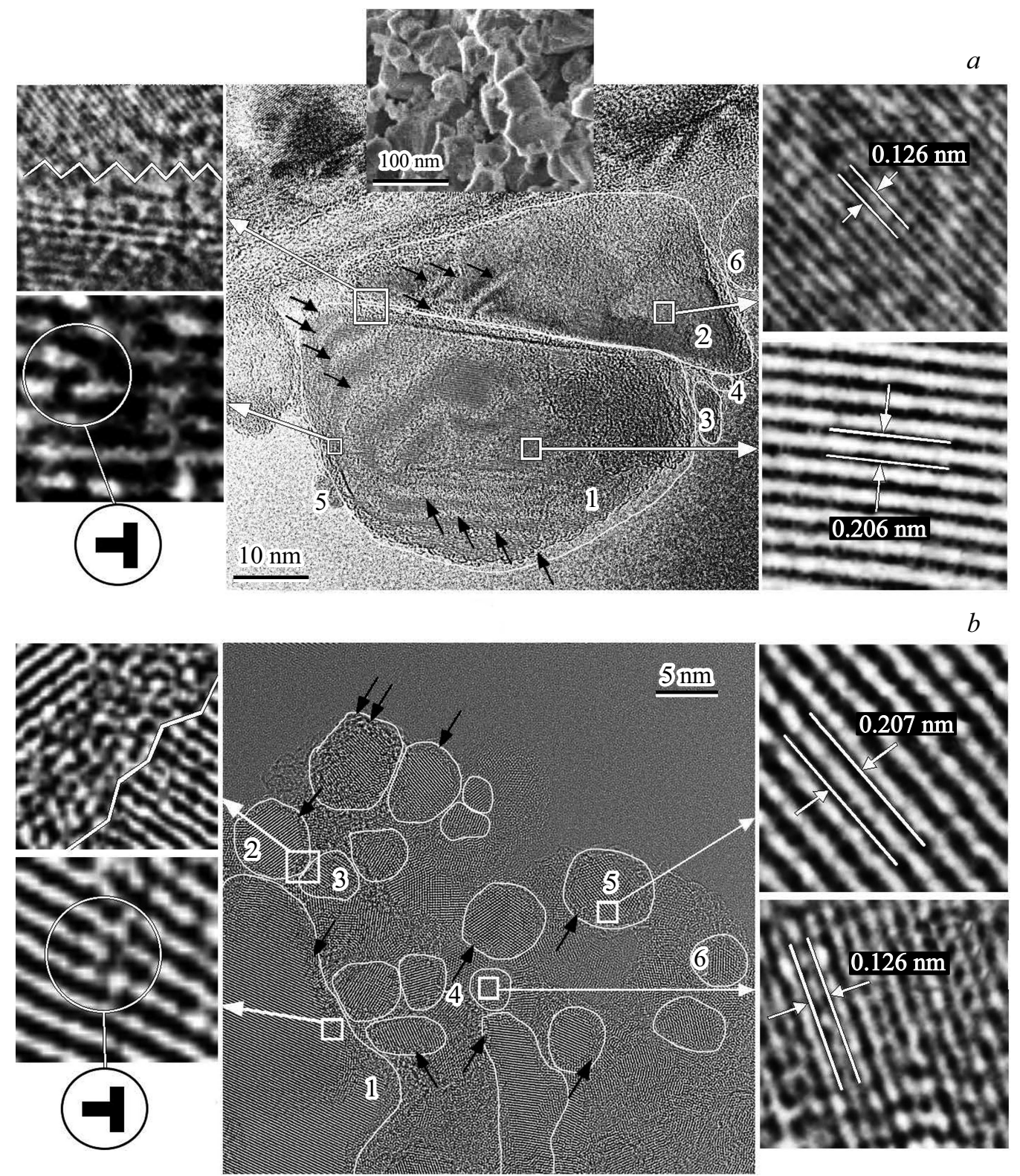

$b$

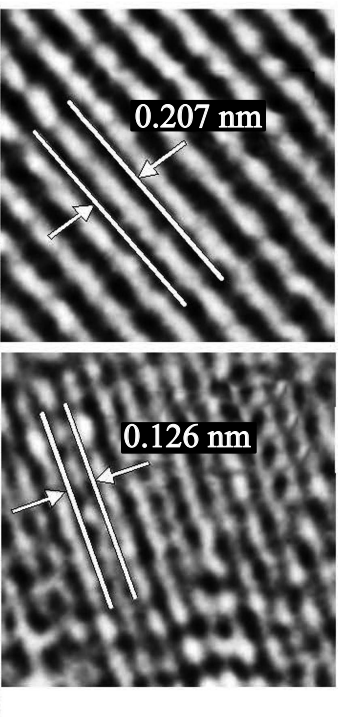

Рис. 2. Изображения атомной структуры первичных частиц нанопорошков ПНА $(a)$ и ДНА $(b)$, полученные с помощью высокоразрешающего ПЭМ в режиме светлого поля при различных увеличениях. Цифрами обозначены номера нанокристаллов, структурные параметры которых приведены в табл. 2.

параметры нанокристаллов, выявить и идентифицировать в них наличие дефектов. В табл. 2 приведены структурные параметры нанокристаллов ПНА и ДНА, определенные исходя из ПЭМ-изображений на рис. 2.
Заметим, что средние значения $d_{h k l}$ нанокристаллов ПНА и ДНА, определенные по их ПЭМ-изображениям, хорошо согласуются с данными, полученными из анализа их дифракционных спектров. Как следует из табл. 2, 

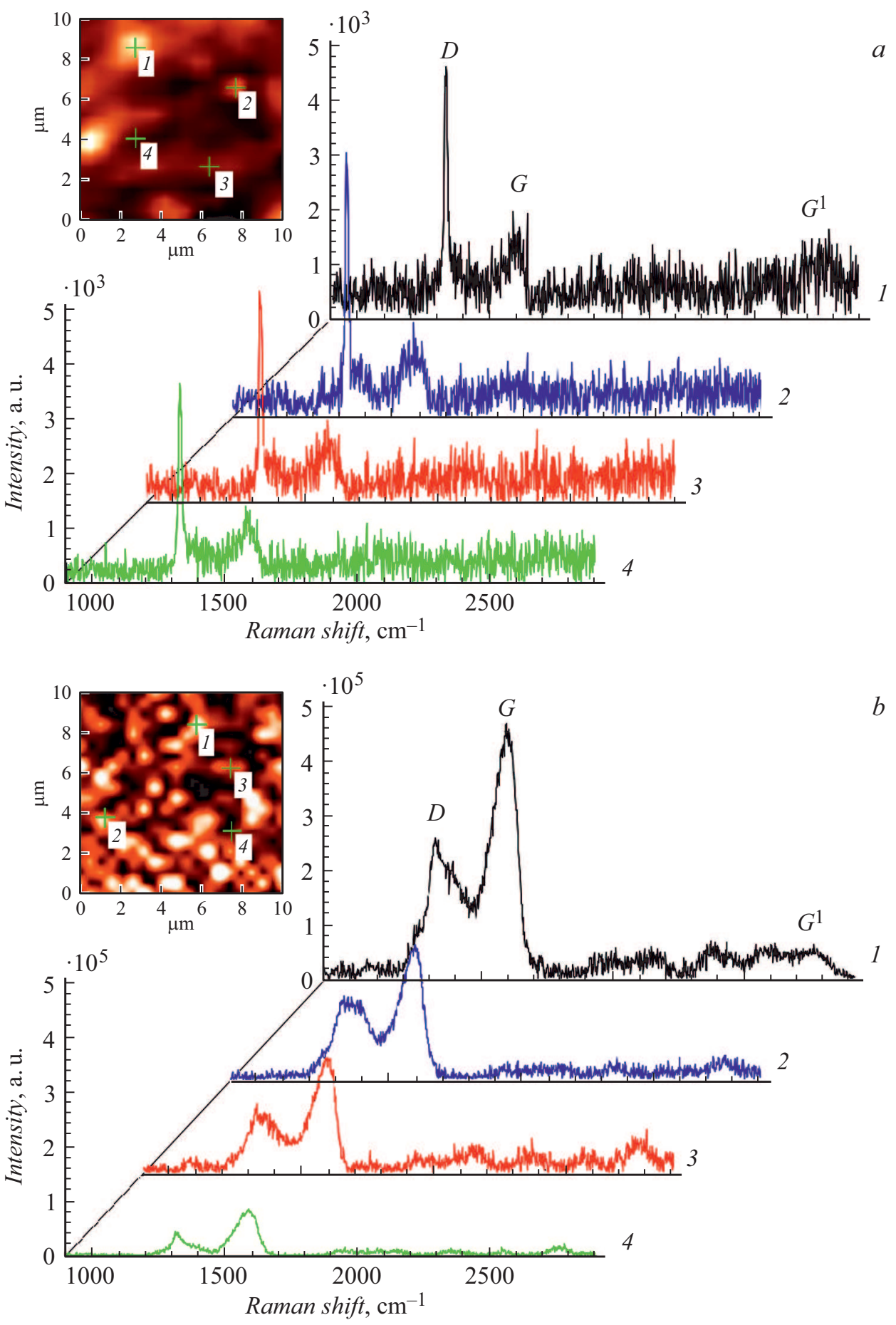

Pис. 3. Двумерные (2D) изображения карты спектров комбинационного рассеяния нанопорошков ПНА $(a)$ и ДНА $(b)$ и вид спектров в четырех произвольных точках, помеченных на карте цифрами.

средние значения $d_{h k l}$ между рядами атомов углерода, а следовательно, и параметры решетки нанокристаллов ДНА заметно больше, чем у нанокристаллов ПНА. В свою очередь параметры решетки ПНА также заметно превышают структурные параметры решетки крупного кристалла алмаза, что указывает на заметное увеличение $d_{h k l}$ в решетках наноалмазов по сравнению с $d_{h k l}$ для массивного кристалла алмаза и экспериментально подтверждает результаты, полученные в работах $[8,9]$. Эффект увеличения $d_{h k l}$ наноалмазов, вероятно, вносит определенный вклад в наблюдаемое снижение плотности нанопорошков ПНА и ДНА по сравнению с плотностью крупных кристаллов алмаза. Однако снижение плотности нанопорошков по сравнению с плотностью массивного кристалла алмаза в основном обусловлено наличием оболочек, неизбежно образующихся на по- 
Таблица 2. Средние значения межплоскостных расстояний $d_{h k l}$, количество атомных плоскостей и их пространственное расположение (индексы Миллера) в нанокристаллах ПНА и ДНА, приведенных на изображениях на рис. 2, $a, b$

\begin{tabular}{|c|c|c|c|c|c|c|}
\hline \multirow[b]{2}{*}{ Порядковый номер кристалла } & \multicolumn{3}{|c|}{ ПНА } & \multicolumn{3}{|c|}{ ДНА } \\
\hline & $d_{h k l}, \AA$ & $\begin{array}{c}\text { Количество атомных } \\
\text { плоскостей }\end{array}$ & $\begin{array}{l}\text { Индексы } \\
\text { Миллера }\end{array}$ & $d_{h k l}, \AA$ & $\begin{array}{c}\text { Количество атомных } \\
\text { плоскостей }\end{array}$ & $\begin{array}{l}\text { Индексы } \\
\text { Миллера }\end{array}$ \\
\hline 1 & 2.062 & 154 & $(111)$ & \multirow[b]{2}{*}{2.071} & 107 & $(111)$ \\
\hline $\begin{array}{l}2 \\
3\end{array}$ & 1.262 & $\begin{array}{r}191 \\
41\end{array}$ & $\begin{array}{l}(220) \\
(220)\end{array}$ & & $\begin{array}{l}25 \\
16\end{array}$ & $\begin{array}{l}(111) \\
(111)\end{array}$ \\
\hline 4 & \multirow{3}{*}{2.062} & 10 & $(111)$ & 1.262 & 8 & $(220)$ \\
\hline 5 & & 14 & $(111)$ & \multirow{2}{*}{2.071} & 21 & $(111)$ \\
\hline 6 & & 20 & $(111)$ & & 10 & $(111)$ \\
\hline
\end{tabular}

верхности первичных частиц наноалмазов при их получении и имеющих плотность более низкую, чем кристаллическое алмазное ядро частиц нанопорошков [10]. Как видно из рис. 2, нанокристаллы ПНА и ДНА покрыты оболочками (некоторые из них выделены на рисунке черными стрелками), состоящими преимущественно из атомов углерода с $s p^{2}$-гибридизацией, что подтверждается их спектрами комбинационного рассеяния (КР). Из рис. 3 видно, что в спектрах КР обоих нанопорошков помимо четко выраженных $D$-линий на частоте вблизи $1332 \mathrm{~cm}^{-1}$, относящихся к углероду с $s p^{3}$-гибридизацией и указывающих на алмазную структуру их решеток, проявляются два широкополосных пика $G$ и $G^{1}$, соответствующих модам атомов углерода в $s p^{2}$-состоянии. В спектре КР проявляется также линия, известная как $D$-пик графита (от „disorder“" $[11]$ ), на частоте с центром $\sim 1350 \mathrm{~cm}^{-1}$ рядом с $D$-линией алмаза. Как видно из рис. 3, в спектре КР нанопорошка ПНА $D$-пик графита выглядит как широкополосное основание с полушириной до $90 \mathrm{~cm}^{-1}$, из которого выступает узкая интенсивная $D$-линия алмаза с полушириной $\sim 14 \mathrm{~cm}^{-1}$, тогда как в спектре ДНА узкая $D$-линия алмаза едва заметна на фоне широкополосного $D$-пика графита. Оболочки из атомов углерода с $s p^{2}$-гибридизацией, содержащие различные примесные атомы и функциональные группы, располагаясь по границам, служат химически активными матрицами, связывающими соседние нанокристаллы алмаза [11]. Изучение и анализ большого количества изображений высокого разрешения (более 40 снимков частиц ПНА и ДНА), аналогичных приведенным на рис. 2, позволили выявить, что наиболее часто встречающимися дефектами в нанокристаллах как ПНА, так и ДНА являются краевые дислокации (см. вставки на рис. 2).

Таким образом, частицы нанопорошка, полученного измельчением, так же как и наноалмазы детонационного синтеза, состоят из алмазных ядер, имеющих кубические кристаллические решетки, окруженные оболочками со сложными структурами, образованными из атомов углерода в $s p^{2}$-состоянии и примесей. Установлено заметное увеличение межатомных расстояний в нанодисперсных кристаллах алмаза по сравнению с таковыми для крупных кристаллов алмаза.

\section{Конфликт интересов}

Авторы заявляют, что у них нет конфликта интересов.

\section{Список литературы}

[1] Nunn N., Torelli M., McGuire G., Shenderova O. // Curr. Opin. Solid State Mater. Sci. 2017. V. 21. N 1. P. 1-9.

[2] Верещагин А.Л. // Южно-сибирский научный вестник. 2017. № 2(18). C. 24-30.

[3] Долматов В.Ю. // Успехи химии. 2001. Т. 70. № 7. С. $677-$ 708.

[4] Новиков Н.В., Богатырева Г.П. // Сверхтвердые материалы. 2008. № 2. С. 3-12.

[5] Шарин П.П., Лебедев М.П., Яковлева С.П., Винокуров Г.Г., Стручков Н.Ф., Кузьмин С.А. // Перспективные материалы. 2014. № 4. С. 58-63.

[6] Михеев К.Г., Шендерова О.А., Когай В.Я., Могилева Т.Н., Михеев Г.М. // Хим. физика и мезоскопия. 2017. Т. 19. № 3. C. 396-406.

[7] http://database.iem.ac.ru/mincryst/rus/s_carta.php?DIAMOND+1165

[8] Яловега Г.Э., Солдатов М.А., Солдатов А.В. // Поверхность. Рентгеновские, синхротронные и нейтронные исследования. 2009. № 7. С. 80-83.

[9] Байдакова М.В., Кукушкина Ю.А., Ситникова А.А., Яговкина М.А., Кириленко Д.А., Соколов В.В., Шестаков М.С., Вуль A.Я., Zousman B., Levinson O. // ФТТ. 2013. Т. 55. В. 8. C. $1633-1639$.

[10] Байтингер Е.М., Беленков Е.А., Брежинская М.М., Грешняков В.А. // ФТТ. 2012. Т. 54. В. 8. С. 1606-1613.

[11] Букалов С.С., Михалицын Л.А., Зубавичус Я.В., Лейтес Л.А., Новиков Ю.Н. // Рос. хим. журн. 2006. Т. L. № 1. C. 83-91. 